Article

\title{
Red Rooibos Tea Stimulates Osteoblast Mineralization in a Dose-Dependent Manner
}

\author{
Michael D. McAlpine ${ }^{1,2, *} \mathbb{C}$, William Gittings ${ }^{1,2}$, Adam J. MacNeil ${ }^{1}\left(\mathbb{D}\right.$ and Wendy E. Ward ${ }^{1,2} \mathbb{C}$ \\ 1 Faculty of Applied Health Sciences, Brock University, St. Catharines, ON L2S 3A1, Canada; \\ wgittings@brocku.ca (W.G.); amacneil@brocku.ca (A.J.M.); wward@brocku.ca (W.E.W.) \\ 2 Centre for Bone and Muscle Health, Brock University, St. Catharines, ON L2S 3A1, Canada \\ * Correspondence: mike.mcalpine@brocku.ca; Tel.: +1-289-808-6360
}

Received: 28 October 2019; Accepted: 27 November 2019; Published: 3 December 2019

check for updates

\begin{abstract}
Most studies show a positive association between higher tea intake and bone mineral density (BMD), while associations with fracture are inconclusive. Although a few studies have investigated the potential effects of rooibos tea on the bone cell metabolism, only 1 or 2 doses were tested or specific flavonoids were evaluated in isolation. A dose-response study is needed to comprehensively identify whether a level that modulates bone cell activity is associated with dietary or supplemental levels of red rooibos (RR) tea. We investigated if RR tea stimulates mineralization in a dose-dependent manner. Mineralization was induced in Saos-2 cells in the presence of RR tea $(0.1-10 \mu \mathrm{g} / \mathrm{mL}$ of polyphenols) or control $\left(\mathrm{dH}_{2} \mathrm{O}\right)$ for 5 days. Cell activity, mRNA, protein expression and activity of key regulators of mineralization were measured. A positive dose-dependent relationship was observed between RR tea concentration and mineralization accompanied with similar trends in cell activity. With high concentrations of tea, protein expression of enzymes directly regulating mineralization (ALP and NPP1) were unchanged but ALP activity was significantly elevated. Osteopontin (OPN) was significantly downregulated midway through mineralization while sclerostin (SOST) was upregulated in response to higher concentrations of RR tea. In conclusion, RR tea stimulated osteoblast mineralization in a dose-dependent manner and were accompanied with downregulation of OPN, increased ALP activity, and increased cell activity.
\end{abstract}

Keywords: antioxidant; mineralization; osteoblast; osteoporosis; polyphenol; reactive oxygen species; red rooibos

\section{Introduction}

Throughout the lifespan, bone is in a constant state of remodeling, a balance between mineral formation and resorption, which are performed by specialized cells known as osteoblasts and osteoclasts, respectively. During childhood and early adulthood this balance favors mineral formation resulting in an increase in bone mineral density (BMD); however, as aging progresses this balance begins to favor increased resorption and a loss in BMD and compromised structure [1]. This imbalance between osteoblast and osteoclast activity as we age is exacerbated even further in women as menopause causes a reduction in estrogen production leading to even greater osteoclast activity and loss of BMD [2]. Over time and depending on the rate of loss, osteoporosis and related fragility fracture may result; common sites of fracture are at the spine, hip, and wrist [3]. Such fractures can be associated with a higher risk of mortality, reduced ability to live independently, compromised mobility and an increased risk of future fracture $[4,5]$. While there are treatments that assist in managing osteoporosis and reducing the risk of future fractures, diet can help support bone health throughout life and may provide a preventive strategy or delay the onset of osteoporosis. 
Beyond calcium and vitamin $\mathrm{D}$, a wide range of foods, nutrients, and food components have been studied for their bone building or supportive actions [6-10]. One potential strategy of promoting and supporting bone health is through the consumption of tea [11]. Consumption of black and green tea is associated with reduced incidence of cancer as well as cardiovascular disease, often attributed to the presence of polyphenols found in tea [12,13]. Polyphenols are a class of compounds found naturally in plants that function as antioxidants by inhibiting the formation and propagation of harmful reactive oxygen species (ROS) [14]. Teas are an abundant source of polyphenols and depending on the plant source as well as the preparation, each tea contains unique polyphenols that alter their ability to function as an antioxidant [15].

The majority of literature regarding bone health and tea consumption has specifically investigated "true teas," which originate from the leaves of the Camellia sinensis plant and include green and black teas. In humans, the association between "true tea" consumption and BMD has been investigated with the majority demonstrating a positive relationship [16-18]. A recent meta-analysis reported a positive trend between "true tea" consumption and BMD [19]. While a higher BMD may be associated with a lower risk of fracture, the current literature regarding "true tea" consumption and fracture incidence is inconclusive with some studies showing beneficial effects (reviewed in [20]) while others conclude that there is no association (reviewed in [21]). This discrepancy could be due to bone strength being the result of not only the quantity (BMD) but also the structure of bone, the latter being more difficult to measure in humans. Researchers have also used rodent models and demonstrated that feeding green or black tea as well as their specific polyphenols improved BMD in an ovariectomized rat model [22-24] as well as an aging female rat model [25].

The mineralization process by osteoblasts is highly regulated by the interaction of many proteins. Two important proteins involved in the balance of inorganic phosphates, and as a result the mineralization process in bone, are alkaline phosphatase (ALP) and ecto-nucleotide pyrophosphatase/ phosphodiesterase (NPP1). The initial step of mineralization by osteoblasts is the formation of hydroxyapatite crystals. ALP plays a role in the hydrolysis of pyrophosphate resulting in inorganic phosphate, while NPP1 is one of the proteins responsible for the formation of inorganic pyrophosphate. Inorganic phosphate stimulates the formation of hydroxyapatite and inorganic pyrophosphate is an inhibitor, making the balance between ALP and NPP1 an important one in the mineralization process [26]. OPN an anionic protein that binds to hydroxyapatite and inhibits further mineral growth is one potent inhibitor of mineralization [27]. Once osteoblasts have been entombed under mineral, they will undergo terminal differentiation to osteocytes which is accompanied by an increase in SOST-a protein produced primarily by osteocytes and a well-defined marker of terminal differentiation of osteoblasts to mature osteocytes [28].

Herbal teas, or more specifically tisanes, are infusions of leaves, seeds, fruit, stems, flowers, or roots from plants other than Camellia sinensis and may present another viable option for promoting and supporting bone health. These infusions have often been used as home remedies to treat symptoms of various health problems and ailments. In terms of variety, there are a wide range of different herbal teas with commonly consumed ones including: chamomile, mint, and rooibos. One particular herbal tea which is gaining popularity among consumers is red rooibos (RR) tea, which originates from the Aspalathus linearis plant found solely in South Africa. RR tea is fully oxidized giving it a flavorful taste as well as a unique polyphenol profile consisting of aspalathin, rutin, orientin, as well as many other flavonoids [29]. Another unique aspect of RR tea is that it is caffeine free, as opposed to green and black teas, making it a desirable alternative for those who are pregnant or caffeine sensitive. Despite the recent increase in popularity there is limited research on the influence of RR tea or other herbals on bone health.

To better understand the direct effects of both "true teas" and herbals on bone formation and resorption, osteoblast, and osteoclast cell models have also been used. In both osteoblast and osteoclast models, cells supplemented with black or green tea or specific polyphenols present in these teas have consistently shown positive effects as measured by increased mineral formation [30-32] and 
reduced bone resorption [33,34]. Previously, two different concentrations of green rooibos tea (1 and $10 \mu \mathrm{g} / \mathrm{mL}$ of polyphenols) had been tested in an osteoblast cell model [32]. Both concentrations demonstrated significant increases in mineralization when compared to control; however, there was no significant difference between the two concentrations. Similar to RR tea, green rooibos tea originates from the Aspalathus linearis plant but is unfermented giving it a different polyphenol profile compared to red rooibos (which is fermented). Another study tested varying concentrations of specific flavonoids, luteolin, and orientin, which are naturally found in RR tea [35]. Researchers observed that both flavonoids increased mineralization in a cell model, but only at certain concentrations. More specifically, orientin significantly increased mineralization at concentrations of $0.1-1 \mu \mathrm{M}$ as well as 15-100 $\mu \mathrm{M}$; while luteolin significantly increased mineralization at $5 \mu \mathrm{M}$. Extracts from both red and green rooibos tea have demonstrated the ability to inhibit the formation of osteoclasts as well as their activity in a rodent cell model suggesting potential health benefits in bone [36]. Furthermore, it was demonstrated that RR tea extracts inhibited osteoclast formation and activity in a dose-dependent manner and were more potent than green rooibos tea extracts. A dose-response in osteoblasts has not been studied and such information will be useful in designing in vivo experiments that aim to investigate the benefit of consuming RR for bone health.

The main objective of this study was to investigate the effects of varying concentrations of RR tea on mineralization in an osteoblast cell model. It was hypothesized that the quantity of mineral produced would increase with increasing RR tea concentration, and based on previous research [32], a plateau in mineralization was anticipated at a concentration lower than $10 \mu \mathrm{g} / \mathrm{mL}$. Dose was an important variable to test as many of the characterized general health benefits of tea are dependent on the amount consumed [37-39].

\section{Materials and Methods}

\subsection{Materials and Chemicals}

Saos-2 cells [40] were obtained from the American type tissue culture (ATCC: Manassas, VA, USA). Ham's F12 cell medium and antibiotic-antimycotic were purchased from Lonza (Mississauga, ON, Canada), while fetal bovine serum (FBS), and trypsin-versene were purchased from GIBCO (Thermo Fisher Scientific, Waltham, MA, USA). Whole-leaf RR tea was purchased from a local specialty tea shop and the same batch was used throughout the experimentation to ensure consistency. Antibodies for proteins of interest as well as reference proteins were purchased from Abcam (Cambridge, UK, USA). All other chemicals, including Folin-Ciocalteau's reagent were purchased from Sigma Aldrich (Oakville, ON, Canada). Consumables were purchased from Sarstedt (Nümbrecht, Germany) and optical density (OD) measurements were determined with a BIO-TEK Synergy HT Multi-Detection Microplate Reader (Winooski, VT, USA). Use of Saos-2 cells was approved by the Brock University Bioscience Research Ethics Board (\#17-347).

\subsection{Preparation of Red Rooibos Tea, Determination of Total Polyphenol Content, and Antioxidant Activity}

RR tea preparations were extracted according to the International Organization of Standardization (ISO 14502-1) with minor changes as previously reported [32]. Total polyphenol content (TPC) of RR tea preparations were measured by Folin-Ciocalteau's method (ISO 14502-1) using gallic acid as a standard [41] and as previously reported [15]. To determine the antioxidant activity of varying concentrations of $R R$ tea preparations (final polyphenol concentrations of 10, 5, 2, 1, 0.75, 0.5, and $0.1 \mu \mathrm{g} / \mathrm{mL}$ of GAE) the ability to scavenge the free radical DPPH was measured, as previously reported [41].

\subsection{Cell Culture}

Saos- 2 cells were sub-cultured weekly at $80 \%$ confluency and maintained at $37{ }^{\circ} \mathrm{C}$ in $5 \% \mathrm{CO}_{2}$ in Ham's F12 media supplemented with 10\% FBS (v/v), 1\% antibiotic/antimycotic (v/v), $2.0 \mathrm{mM}$ 
L-glutamine, $28 \mathrm{mM}$ HEPES buffer, and $1.0 \mathrm{mM} \mathrm{CaCl}_{2}$ (Media-1). To initiate osteoblastic differentiation, cells were seeded in 24-well plates at a density of $1 \times 10^{4}$ cells/well and media- 1 was supplemented with $10 \mathrm{nM}$ dexamethasone and $50 \mu \mathrm{g}$ ascorbic acid/mL (Media-2). Following 8 days of differentiation, Media-2 was further supplemented with $10 \mathrm{mM} \beta$-glycerophosphate and either a control vehicle $\left(\mathrm{dH}_{2} \mathrm{O}\right)$ or varying concentrations of $\mathrm{RR}$ tea preparations (final polyphenol concentrations of 10,5 , $2,1,0.75,0.5$, or $0.1 \mu \mathrm{g} / \mathrm{mL}$ of GAE) to induce mineralization (Media-3). These doses were chosen to encompass a wide range of quantities; $1 \mu \mathrm{g} / \mathrm{mL}$ is representative of what would likely be consumed through diet (2-3 cups/day) while $10 \mu \mathrm{g} / \mathrm{mL}$ would be an amount consumed through supplementation (20-30 cups/day). All experiments were done with cells between passage 50-60 and media was replenished every 2 or 3 days. RR tea was added following proliferation and differentiation to ensure that any differences observed occurred during the mineralization phase.

\subsection{Mineralization}

To quantify mineralization, cells were stained with alizarin red S (ARS) as previously described [42]. In brief, following 5 days of mineralization, media was removed and Saos- 2 cells were washed with phosphate-buffered saline (PBS). Following aspiration of PBS, cells were fixed by the addition of $500 \mu \mathrm{L}$ of $4 \%$ paraformaldehyde and allowed to incubate overnight at $4{ }^{\circ} \mathrm{C}$. The following day paraformaldehyde was removed and cell monolayer was washed twice with $\mathrm{dH}_{2} \mathrm{O}$. After washing, $500 \mu \mathrm{L}$ of ARS ( $40 \mathrm{mM}, \mathrm{pH} 4.2$ ) was added to each well and allowed to incubate for $20 \mathrm{~min}$ at room temperature on an orbital shaker. Cells were subsequently washed another four times with $\mathrm{dH}_{2} \mathrm{O}$ to remove any excess dye. Next, $500 \mu \mathrm{L}$ of cetylpyridinium chloride was added to each well and gentle agitation by an orbital shaker was applied for $1 \mathrm{~h}$ at room temperature to solubilize dye for measurement of OD. Aliquots $(150 \mu \mathrm{L})$ from each well were transferred in triplicate to a 96-well plate and the resulting absorbance was measured at $550 \mathrm{~nm}$.

\subsection{Cellular Activity Assay}

To compare the effects of RR tea concentration on cell activity, as well as cellular viability, a 3-(4,5-dimethylthiazol-2-yl)-2,5-diphenyltetrazolium bromide (MTT) assay was performed [43]. Cells were seeded in 96-well plates at a density of $1 \times 10^{4}$ cells/well in media- 1 for $24 \mathrm{~h}$. After cells adhered for $24 \mathrm{~h}$, media was aspirated and cells were washed with PBS. Media- 1 supplemented with varying concentrations of RR tea $\left(10,5,2,1,0.75,0.5\right.$, or $0.1 \mu \mathrm{g} / \mathrm{mL}$ of polyphenols) or a control vehicle $\left(\mathrm{dH}_{2} \mathrm{O}\right)$ was added to the cells. Following 24 or $48 \mathrm{~h}$ of tea or control vehicle exposure, MTT $(5 \mathrm{mg} / \mathrm{mL})$ in the absence of tea was added to each well and cells were incubated at $37^{\circ} \mathrm{C}$ for $4 \mathrm{~h}$. After incubation, crystals were solubilized with the addition of $100 \mu \mathrm{L} 10 \%$ SDS (w/v) in $10 \mathrm{mM} \mathrm{HCl}$ and incubation overnight followed by $30 \mathrm{~min}$ of gentle agitation by orbital shaker. The resulting OD of the solution was measured at $570 \mathrm{~nm}$ with the background read at $690 \mathrm{~nm}$ being subtracted.

\section{6. $R T-q P C R$}

The expression of genes (ALP, NPP1, OPN, and SOST) were quantified following 3 and 5 days of mineralization using a StepOnePlus real time polymerase chain reaction (PCR) system (Applied Biosystems: Foster City, CA, USA) and KAPA SYBR Fast (Kapa Biosystems: Wilmington, MA, USA) as previously described [44]. Total RNA was extracted from cells using an RNeasy@ plus mini kit (Qiagen: Hilden, Germany) according to manufacturer's recommendations. Following extraction, purity and quantity of collected RNA was assessed using a NanoVue Plus system (Biochrom, Holliston, MA, USA). RNA was then reverse-transcribed to cDNA using EcoDry double-primed premix (Clontech: Mountain View, CA, USA). Primers were synthesized by Integrated DNA Technologies (IDT: Coralville, IA, USA) and validated for amplification efficiency and target specificity in the Saos-2 cell model prior to testing. Samples were run in duplicate on a 96-well reaction plate and analyzed using the $2^{-\Delta \Delta C T}$ method with GAPDH as a reference gene. Specific forward and reverse primer sequences can be found in Table S1. 


\subsection{Immunoblotting}

After 3 and 5 days of mineralization, Saos- 2 cells were lysed and protein was extracted with radioimmunoprecipitation assay (RIPA) buffer containing phosphatase (PhosSTOP) and protease (cOmplete) inhibitors. Protein content was measured by Bradford assay and samples were separated by sodium dodecyl sulfate-polyacrylamide gel electrophoresis (SDS-PAGE). Following separation, protein was transferred to a $0.2 \mu \mathrm{m}$ polyvinylidene fluoride (PVDF) membrane and subsequently blocked and probed with the corresponding antibodies for the proteins of interest (ALP, NPP1, OPN, and SOST) in either $5 \%(\mathrm{w} / \mathrm{v})$ bovine serum albumin (BSA) or $5 \%(\mathrm{w} / \mathrm{v})$ non-fat milk in tris-buffered saline and tween-20 (TBST). Membranes were then visualized using a FluorChem system (Alpha Innotech, San Leandro, CA, USA) and densitometry analysis was completed using Image Studio Lite software. Specific immunoblotting conditions and antibodies for each protein can be found in Table S2.

\subsection{ALP Activity Assay}

Following 3 and 5 days of mineralization the activity of ALP was determined by quantifying the dephosphorylation of p-nitrophenol phosphate (pNPP) [45]. In brief, cells were rinsed twice with 50 $\mathrm{mM}$ Tris- $\mathrm{HCl}(\mathrm{pH} 7.35)$ then scraped in $500 \mu \mathrm{L}$ of $0.05 \%$ Triton- $\mathrm{X} 100$ Tris- $\mathrm{HCl}$ and transferred to $1.5-\mathrm{mL}$ Eppendorf tubes. Eppendorfs were then agitated and centrifuged for $10 \mathrm{~min}$ at $10000 \mathrm{rpm}$, and the supernatant was collected in fresh tubes. To $25 \mu \mathrm{L}$ of cell sample, $\mathrm{MgCl}_{2}$-Sigma 221 Buffer $(90 \mu \mathrm{L})$ and pNPP solution $(10 \mu \mathrm{L})$ was added and the reaction proceeded for $5 \mathrm{~min}$ at room temperature and stopped through the addition of $0.5 \mathrm{M} \mathrm{NaOH}$ and transfer to ice. Samples were then read at an OD of $405 \mathrm{~nm}$. All readings were normalized to protein content determined through Bradford assay.

\subsection{NPP1 Activity Assay}

The activity of NPP1 was determined at day 3 and 5 of mineralization by quantifying the hydrolysis of p-nitrophenyl $5^{\prime}$-thymidine monophosphate (p-Nph-5'-TMP) and the resulting change in color [46]. Cells were rinsed twice with $50 \mathrm{mM}$ Tris- $\mathrm{HCl}$ (pH 7.35) then scraped in $500 \mu \mathrm{L}$ of $0.05 \%$ Triton-X100 Tris- $\mathrm{HCl}$ and transferred to 1.5-mL Eppendorf tubes. Eppendorfs were then agitated and centrifuged for $10 \mathrm{~min}$ at 10,000 rpm, and the supernatant was collected in fresh tubes. $40 \mu \mathrm{L}$ of cell sample was then mixed with $45 \mu \mathrm{L}$ of buffer (Tris- $\mathrm{HCl}, \mathrm{KCl}, \mathrm{NaCl}$, and glucose) and $20 \mu \mathrm{L}$ of $5 \mathrm{mM} \mathrm{p}-\mathrm{Nph}-5^{\prime}-\mathrm{TMP}$. Following $75 \mathrm{~min}$ of incubation at $37^{\circ} \mathrm{C}$ the reaction was stopped with $0.2 \mathrm{M} \mathrm{NaOH}$ and the resulting mixture was read at $405 \mathrm{~nm}$. All readings were normalized to protein content determined through Bradford assay.

\subsection{Statistical Analysis}

One-way ANOVA were conducted to assess differences in mineralization, cellular activity, gene expression, and protein expression. Differences between means were deemed significantly different if $p<0.05$. If a significant difference was observed in any of the statistical analyses, Tukey's post-hoc test was performed to further identify where the specific differences were located. All statistical analysis was conducted using GraphPad Prism ${ }^{\mathrm{TM}}$ V5 (La Jolla, CA, USA). Results are reported as mean (\% of control) \pm SEM (with the exception of gene expression; which is expressed as mean fold change compared to control \pm SEM).

\section{Results}

\subsection{Antioxidant Activity}

The ability of RR tea to inhibit the free radical DPPH differed between concentrations $(p<0.05)$ (Figure 1). More specifically, there was a dose-dependent relationship whereby increasing concentrations of RR tea elicited greater inhibition of DPPH except for concentrations of 0.5 and $0.75 \mu \mathrm{g} / \mathrm{mL}$ as well as 5 and $10 \mu \mathrm{g} / \mathrm{mL}$. 


\section{Antioxidant Activity}

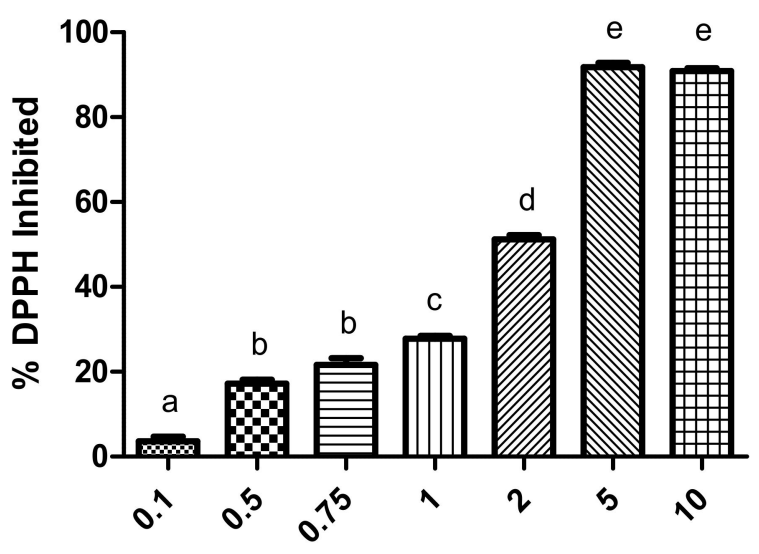

Red Rooibos Concentration $(\mu \mathrm{g} / \mathrm{mL})$

Figure 1. Ability of varying red rooibos (RR) tea polyphenols to function as antioxidants and inhibit the free radical DPPH. Error bars are $\pm \mathrm{SEM}, n=5$. Differing letters indicates a significant difference $(p<0.05)$ among rooibos concentrations.

\subsection{Mineralization}

Following 5 days of mineralization, the amount of mineral produced by Saos- 2 cells varied greatly depending on the concentration of RR tea (Figure 2a,b). When supplemented with tea at concentrations $\geq 0.5 \mu \mathrm{g} / \mathrm{mL}$ of polyphenols, cells produced significantly greater $(p<0.05)$ quantities of mineral than those receiving vehicle control. When comparing the effectiveness of varying concentrations of RR tea on mineralization there is a dose-dependent relationship, with greater concentrations of tea yielding greater mineral production.

a)

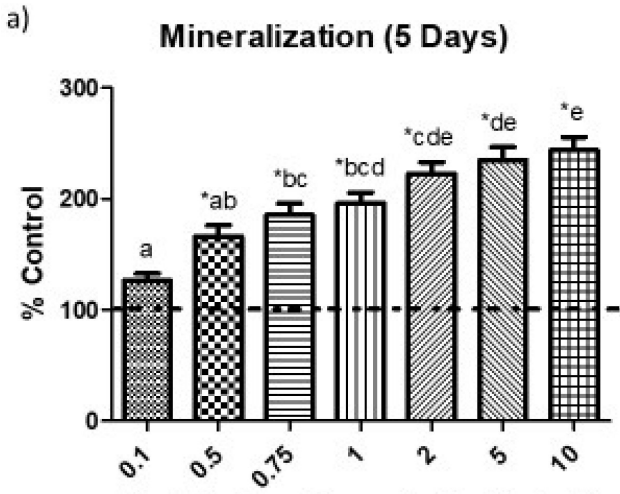

\section{Red Rooibos Concentration ( $\mu \mathrm{g} / \mathrm{mL}$ )}

b)

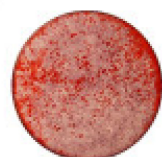

0.1

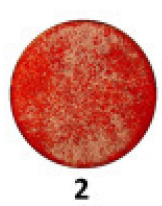

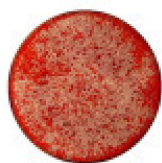

0.5

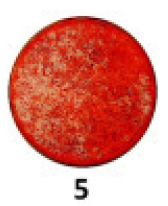

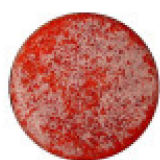

0.75

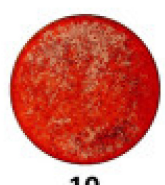

10

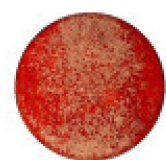

1

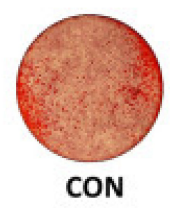

Figure 2. Influence of RR tea polyphenol concentration on mineralization. (a) Mineralization after 5 days in the presence or absence of RR tea polyphenols; error bars are \pm SEM, $n=5$ (each sample was the resulting average of three wells). $\mathrm{CON}=$ control. ${ }^{*}$ indicates a significant difference $(p<0.05)$ between rooibos concentration and control, while differing letters indicate a significant difference $(p<0.05)$ among concentrations. (b) Images of representative alizarin red stain showing mineralization.

\subsection{Cell Activity}

To investigate if RR tea influenced cellular activity, the formation of formazan crystals was measured following 24 and $48 \mathrm{~h}$ of incubation in the presence of RR tea preparations or a control vehicle and the subsequent addition of MTT. Results indicate that following $24 \mathrm{~h}$ there was a significantly $(p<0.05)$ higher cell activity in cells receiving tea preparations with $\geq 0.5 \mu \mathrm{g} / \mathrm{mL}$ of polyphenols than control, and cells that received RR tea with $10 \mu \mathrm{g} / \mathrm{mL}$ of polyphenols had the greatest cell activity (Figure 3a). After $48 \mathrm{~h}$, all concentrations of RR tea elicited significantly greater cell activity than 
control, with concentrations of $10 \mu \mathrm{g} / \mathrm{mL}$ having the greatest cell activity followed by $0.5-5 \mu \mathrm{g} / \mathrm{mL}$ and then $0.1 \mu \mathrm{g} / \mathrm{mL}$ of polyphenols (Figure $3 \mathrm{~b}$ ).
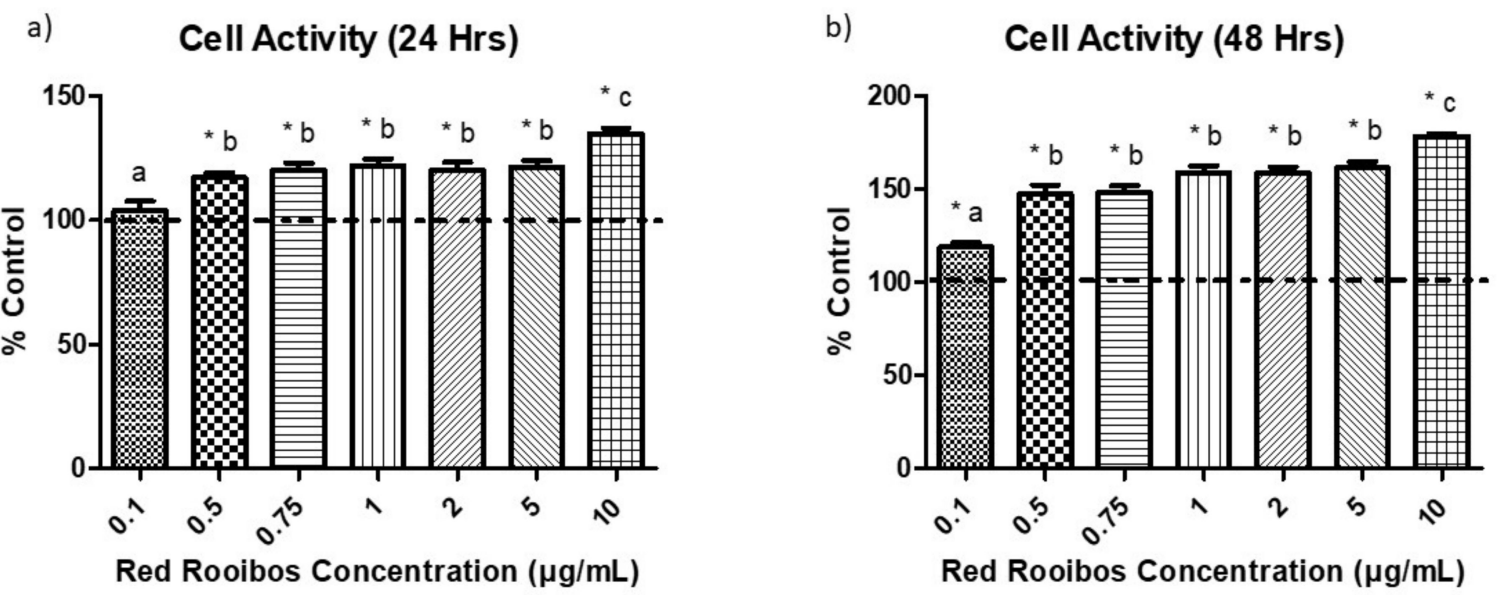

Figure 3. Cell activity following exposure to varying concentrations of RR tea polyphenols for (a) $24 \mathrm{~h}$; and (b) 48 h. Quantity of MTT (3-(4,5-dimethylthiazol-2-yl)-2,5-diphenyltetrazolium bromide) reduced to formazan crystals expressed as \% of control. Error bars are $\pm \mathrm{SEM}, n=12$. CON $=$ control. * indicates a significant difference $(p<0.05)$ between rooibos concentration and control, while differing letters indicate a significant difference $(p<0.05)$ among concentrations.

\subsection{Expression of ALP, NPP1, SOST, and OPN Genes}

Following 3 and 5 days of mineralization, the expression of several genes were assessed to elucidate potential mechanisms behind alterations in mineral production elicited by the presence of RR tea.

\subsubsection{Mineralization Day 3 (Gene Expression)}

After 3 days of mineralization there were no differences in $A L P$ expression between cells that were exposed to lower concentrations of $R R$ tea $(\leq 2 \mu \mathrm{g} / \mathrm{mL}$ of polyphenols) and the control vehicle $\left(\mathrm{dH}_{2} \mathrm{O}\right)$. However, at concentrations $\geq 5 \mu \mathrm{g} / \mathrm{mL}$ or higher there is a statistically significant $(p<0.05)$ decrease in $A L P$ ( $A L P L$ ) expression (Figure 4a). NPP1 (ENPP1) expression remained similar between all conditions regardless of RR tea concentration (Figure $4 b$ ). SOST remained unchanged at lower concentrations $(\leq 2 \mu \mathrm{g} / \mathrm{mL})$ but expression was significantly $(p<0.05)$ increased, when supplemented with higher concentrations of RR tea ( $\geq 5 \mu \mathrm{g} / \mathrm{mL}$ of polyphenols) relative to cells treated with control vehicle (Figure 4c). Levels of OPN (SPP1) expression were similar across all concentrations after 3 days of mineralization with no statistical differences among them $(p<0.05)$ (Figure $4 \mathrm{~d})$. 


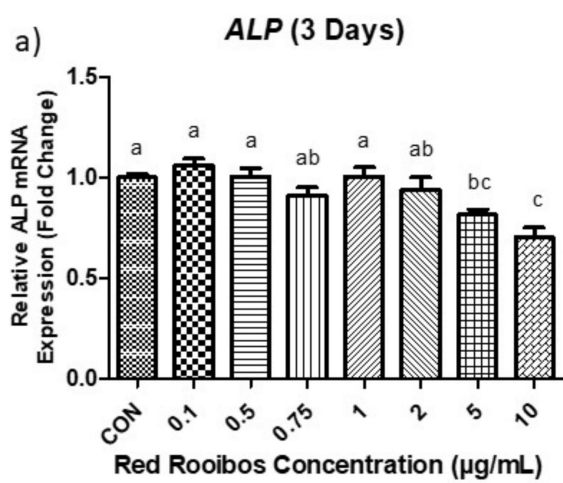

c)

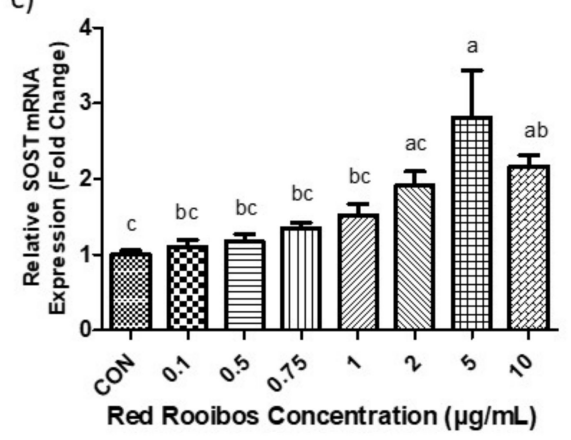

b)

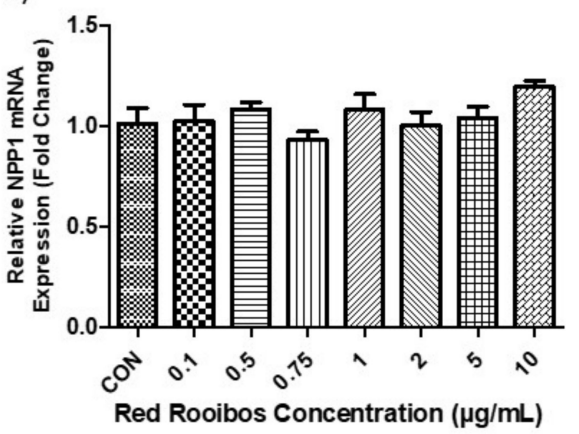

d)

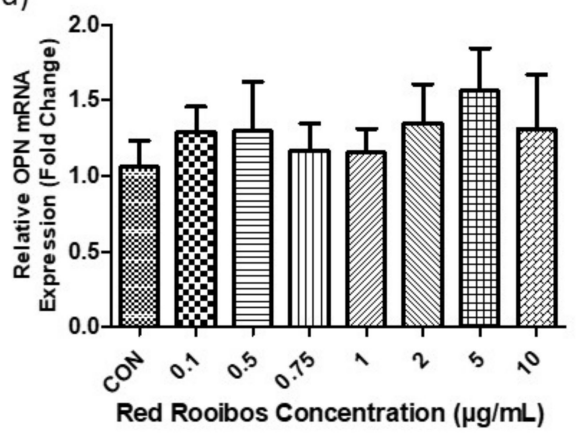

Figure 4. Gene expression following 3 days of mineralization. (a) ALP; (b) NPP1; (c) SOST; (d) OPN. Values expressed as fold change compared to control condition $\left(\mathrm{dH}_{2} \mathrm{O}\right)$. Error bars are $\pm \mathrm{SEM}, n=6$. $\mathrm{CON}=$ control. Differing letters indicate a significant difference $(p<0.05)$ among conditions.

\subsubsection{Mineralization Day 5 (Gene Expression)}

Following 5 days of mineralization $A L P$ expression in Saos- 2 cells were significantly decreased $(p<0.05)$ when supplemented with concentrations of $\mathrm{RR}$ tea $\geq 2 \mu \mathrm{g} / \mathrm{mL}$ of polyphenols compared to control (Figure 5a). Cells supplemented with RR tea at a concentration of $0.1 \mu \mathrm{g} / \mathrm{mL}$ of polyphenols also demonstrated significantly elevated $A L P$ expression when compared to all other conditions receiving polyphenols. Similarly, NPP1 expression differed $(p<0.05)$ among concentrations, with cells supplemented with RR tea at concentrations $\geq 2 \mu \mathrm{g} / \mathrm{mL}$ of polyphenols exhibiting reduced expression compared to the other concentrations (Figure 5b). Once again, in terms of SOST expression, significant differences were observed in cells receiving RR tea at concentrations $\geq 2 \mu \mathrm{g} / \mathrm{mL}$ of polyphenols or greater when compared to control. More specifically, these cells had elevated levels of SOST expression compared to control (Figure $5 \mathrm{c}$ ). In contrast, after 5 days of mineralization there were significant differences $(p<0.05)$ among the expression of OPN by cells supplemented with RR tea at concentrations $\geq 0.5 \mu \mathrm{g} / \mathrm{mL}$ of polyphenols and those supplemented with lower concentrations $(0.1 \mu \mathrm{g} / \mathrm{mL})$ or a control vehicle; with the former exhibiting decreased OPN expression (Figure 5d). 

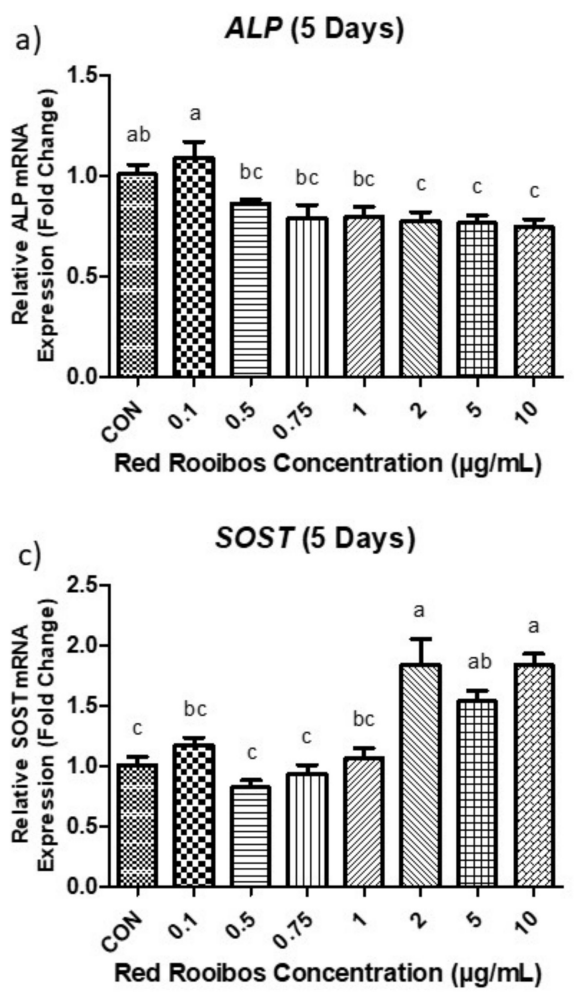
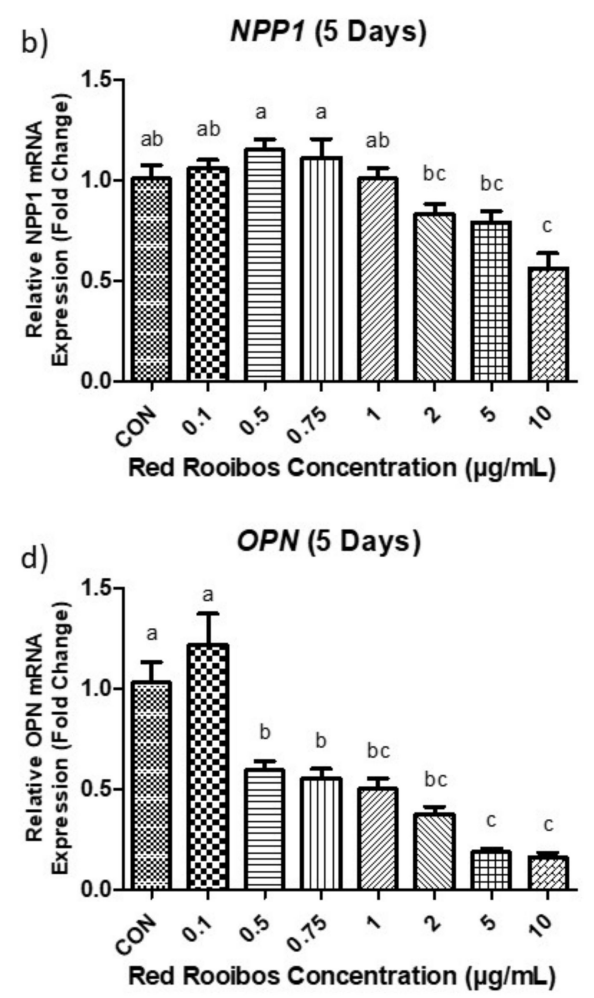

Figure 5. Gene expression following 5 days of mineralization. (a) ALP; (b) NPP1; (c) SOST; (d) OPN. Values expressed as fold change compared to control condition $\left(\mathrm{dH}_{2} \mathrm{O}\right)$. Error bars are $\pm \mathrm{SEM}, n=6$. $\mathrm{CON}=$ control. Differing letters indicate a significant difference $(p<0.05)$ among conditions.

\subsection{Protein Expression of ALP, NPP1, SOST, and OPN}

To uncover mechanistic alterations potentially responsible for the observed changes in mineralization, protein expression of ALP, NPP1, SOST, and OPN were assessed following 3 and 5 days of mineralization.

\subsubsection{Mineralization Day 3 (Protein Expression)}

Three days into the mineralization process, protein expression remained mostly unchanged when compared to control with the exception of OPN (Figure 6a). More specifically, there were no observed differences in ALP, NPP1, and SOST (Figure 6b-d); while OPN was significantly reduced at RR tea concentrations $\geq 0.5 \mu \mathrm{g} / \mathrm{mL}$ of polyphenols when compared to control (Figure 6e). 

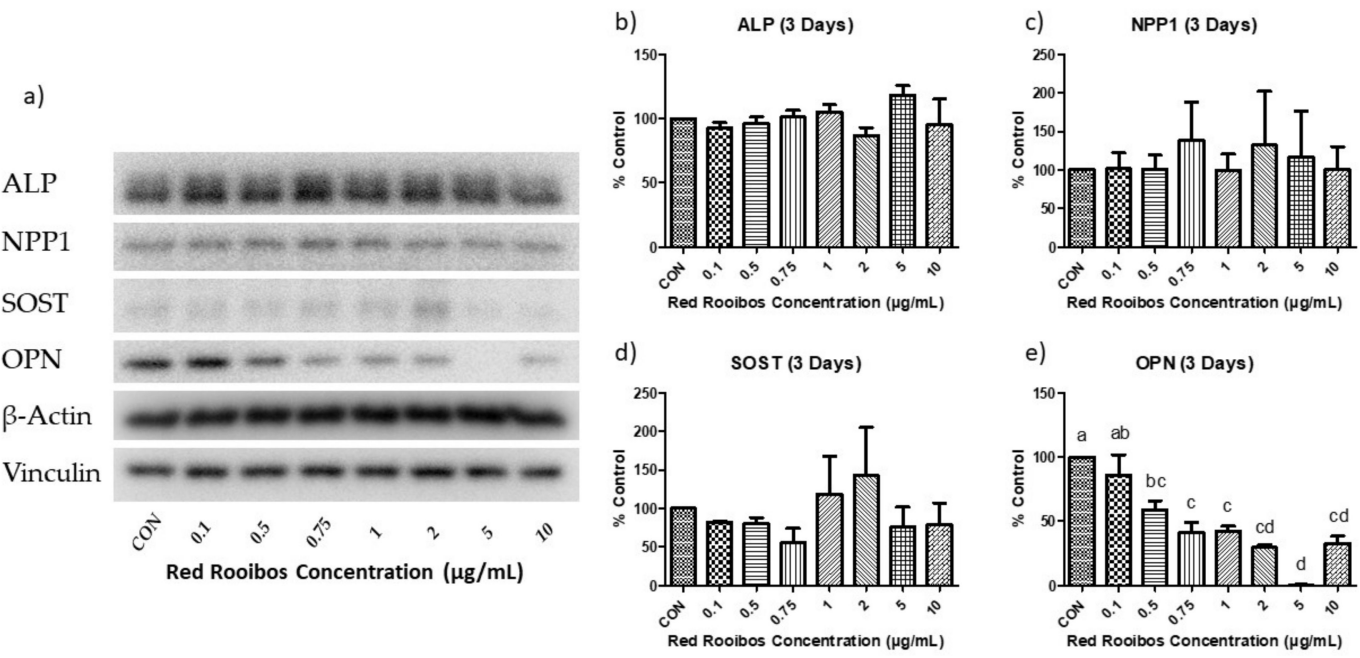

Figure 6. Protein expression following 3 days of mineralization. (a) representative Western blot analysis of the influence of RR tea polyphenols on Saos-2 cells. Densitometric analysis of (b) ALP; (c) NPP1; (d) SOST; and (e) OPN protein expression. Values are normalized to reference protein (Vinculin; ALP, OPN, SOST, and $\beta$-actin: NPP1) and presented as $\%$ of control with error bars $\pm \mathrm{SEM}, n=3$. Differing letters indicate a significant difference $(p<0.05)$ among conditions.

\subsubsection{Mineralization Day 5 (Protein Expression)}

Protein expression was determined after 5 days of mineralization in the presence or absence of RR tea (Figure 7a). After 5 days of mineralization, the expression of ALP and NPP1 remained unchanged, with no significant differences between any of the concentrations (Figure $7 \mathrm{~b}, \mathrm{c}$ ). The protein expression of SOST, which was previously unaltered among concentrations after 3 days of mineralization, demonstrated a significant difference $(p<0.05)$ between cells receiving RR tea at a concentration of $1 \mu \mathrm{g} / \mathrm{mL}$ of polyphenols and control, with the former producing elevated levels of SOST (Figure 7d). Concentrations $>1 \mu \mathrm{g} / \mathrm{mL}$ appeared to also have elevated levels of SOST; however, it was not statistically significant. In terms of OPN protein expression, the large differences present following 3 days of mineralization disappeared, and no significant differences were observed (Figure 7e).

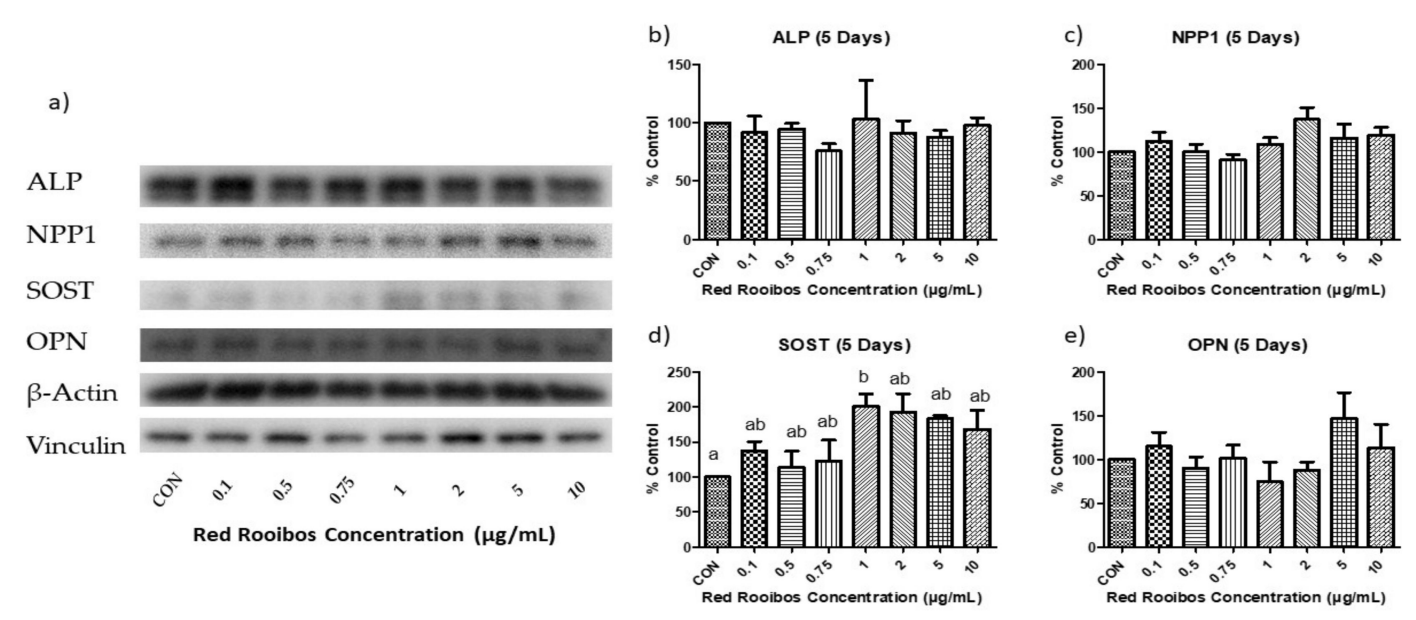

Figure 7. Protein expression following 5 days of mineralization. (a) representative western blot analysis of the influence of red rooibos polyphenols on Saos-2 cells. Densitometric analysis of (b) ALP; (c) NPP1; (d) SOST; and (e) OPN protein expression. Values are normalized to reference protein (Vinculin; ALP, OPN, SOST and $\beta$-actin: NPP1) and presented as $\%$ of control with error bars $\pm \mathrm{SEM}, n=3$. Differing letters indicate a significant difference $(p<0.05)$ among conditions. 


\subsection{ALP and NPP1 Activity}

The specific activity of ALP and NPP1, key proteins involved in the mineralization process by osteoblasts, were investigated following 3 and 5 days of mineralization. Following 3 days of mineralization the activity of both ALP and NPP1 significantly differed from the control in response to $R R$ tea. Concentrations of RR tea at concentrations $\leq 2 \mu \mathrm{g} / \mathrm{mL}$ of polyphenols elicited similar ALP activity than cells which had received a volume control. While concentrations $\geq 5 \mu \mathrm{g} / \mathrm{mL}$ resulted in significantly $(p<0.05)$ elevated activity (Figure 8a). In terms of NPP1, RR tea resulted in little alteration to activity when compared to control with the exception of cells receiving $2 \mu \mathrm{g} / \mathrm{mL}$ which demonstrated a significantly reduced activity after 3 days of mineralization $(p<0.05)$ (Figure 8b). Following 5 days of mineralization the activity of ALP and NPP1 were similar among groups regardless of RR concentration (Figure $8 \mathrm{c}, \mathrm{d}$ ).

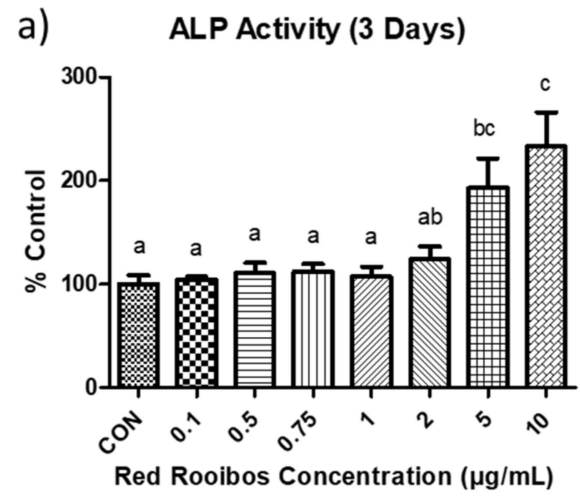

c)

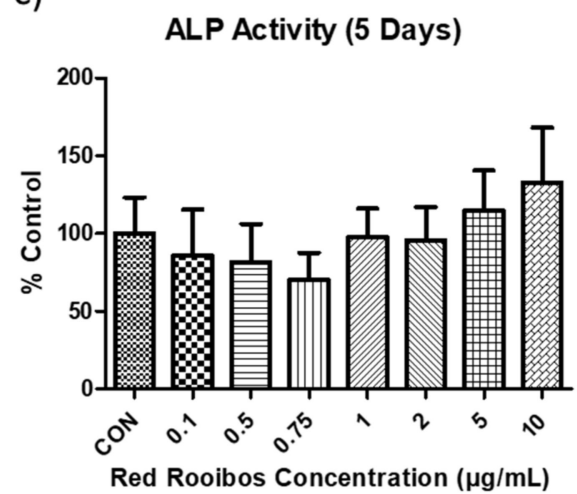

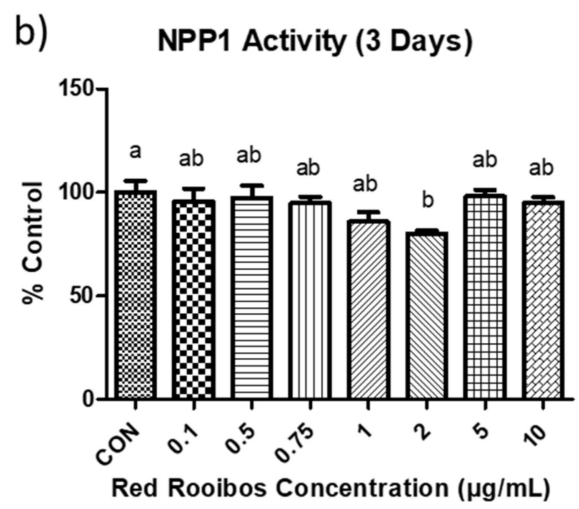

d)

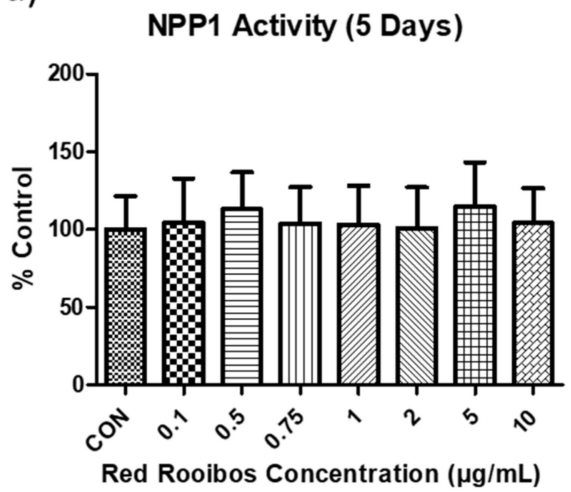

Figure 8. Activity of (a) ALP (3 days); (b) NPP1 (3 days); (c) ALP (5 days); and (d) NPP1 (5 days) in the presence or absence of tea during mineralization. Values are presented as $\%$ of control with error bars $\pm \mathrm{SEM}, \mathrm{CON}=$ control, $n=5$ or 6 . Differing letters indicate a significant difference $(p<0.05)$ among conditions.

\section{Discussion}

The study findings demonstrate that RR tea is capable of increasing mineralization by osteoblasts in a dose-dependent manner, whereby higher concentrations yielded higher mineral production. The mineralization process in osteoblasts has been shown to be influenced by the amount of oxidative stress present [47]. More specifically, greater amounts of ROS in relation to antioxidants will in turn elicit a low amount of mineralization and vice versa supporting our finding that higher RR tea concentration, and in turn polyphenols and antioxidants, elicited higher mineralization [48,49].

The accumulation of ROS and the corresponding oxidative stress have been shown to directly influence the osteoblast viability. In relation to osteoblasts, ROS can induce apoptosis as well as reduce differentiation $[50,51]$. In contrast, $N$-acetyl cysteine, a potent antioxidant, has been shown 
to inhibit osteoblastic apoptosis as well as increase osteoblast differentiation $[52,53]$. These previous studies support the current finding that cell viability, measured by the reduction of MTT, increased with increasing RR tea concentrations. Polyphenols from black, green, and rooibos teas have previously demonstrated antioxidant abilities in vitro and in vivo [14,15]. In the present study, higher concentrations of RR tea elicited higher cell viability. Although not directly measured, this could possibly be due to a greater inhibition of ROS by polyphenols in RR tea. As well, larger differences in cell viability between $R R$ concentration and control were seen following $48 \mathrm{~h}$. This could be explained by a potentially greater accumulation of ROS in control cells following $48 \mathrm{~h}$ compared to $24 \mathrm{~h}$, leading to a larger amount of oxidative stress. Although not evaluated in the current study, oxidative stress also influences osteocytes as well as osteoclasts. More specifically, ROS has been shown to increase osteoclast differentiation and osteocyte apoptosis [54,55].

Past research has demonstrated that addition of tea to osteoblasts corresponds with higher amounts of ALP $[32,35,56]$; however, there is currently no literature on how tea influences the NPP1 gene and protein expression. In the present study there were slight reductions in ALP gene expression following 3 and 5 days of mineralization in the presence of higher RR tea concentrations; while NPP1 gene expression remained unchanged until 5 days of mineralization, where it was reduced at higher concentrations. However, after translation of the genes, there were no statistical differences in ALP and NPP1 protein expression at any time point. This suggests that in the present study RR tea induces minimal alterations in terms of ALP and NPP1 protein expression. Despite similar protein expression of ALP, there was a significantly higher activity at 3 days of mineralization in cells that received RR tea at concentrations $\geq 5 \mu \mathrm{g} / \mathrm{mL}$ of RR polyphenols. This finding suggests that at day 3 of mineralization RR tea can increase the activity of ALP and may partially explain the ability of RR tea to induce increased mineralization by osteoblasts. It is also possible that there were alterations in other proteins that regulate mineralization but were not investigated, including phosphoethanolamine/phosphocholine phosphatase (PHOSPHO1) and progressive ankylosis protein homolog (ANKH) proteins.

Following 5 days of mineralization OPN gene expression was reduced in cells receiving RR tea at concentrations of $\geq 0.5 \mu \mathrm{g} / \mathrm{mL}$ of polyphenols, and OPN protein expression was significantly reduced at similar concentrations following 3 days but were absent at 5 days. The observed reductions in OPN gene and protein expression support the concurrent increases in mineralization with higher concentrations of RR tea and may provide a mechanism to explain the observed effects. Another proposed function of OPN is that it is capable of sensing ROS and in turn reacting to oxidant stress by altering its expression [57]. These studies observed that in response to ROS, OPN was subsequently upregulated which support the alterations in OPN found in this study.

In the present study, following 3 days of mineralization SOST gene expression was elevated with higher concentrations of RR tea, an effect that persisted to 5 days. Protein expression of SOST was also upregulated following 5 days of mineralization at higher concentrations. These findings suggest that higher concentrations of RR tea may lead to induced osteoblast differentiation to osteocytes. Saos-2 cells have previously been shown to be capable of transitioning to osteocytes under mineralizing conditions confirmed by the appearance of dendritic extensions and expression of SOST [58]. SOST primarily functions to inhibit Wnt signaling which is a key pathway involved in osteoblast differentiation and subsequent bone formation by osteoblasts [59]. However, in the current study Saos-2 cells were supplemented with ascorbic acid and dexamethasone (Media- 2) for 8 days prior to the addition of $\beta$-glycerophosphate (Media-3) and the initiation of mineralization to ensure differentiation before the addition of test conditions.

A limitation of the present study is the use of a cell model in which osteoblasts are isolated from all other physiological systems that can regulate bone cell activity. Thus, the mechanism by which RR tea stimulated mineralization by osteoblasts in a dose-dependent manner requires further study. Though, RR tea may exert its effect, at least partially, by functioning as antioxidants and possibly decreasing the amount of ROS and oxidant stress within the cell and increasing cell viability. This in turn may downregulate the expression of OPN, leading to a reduced inhibition of 
mineralization. As greater quantities of mineral are produced, osteoblasts would become entombed and differentiate to mature osteocytes, increasing SOST. Findings also suggest that increased levels of ALP activity with higher concentrations of RR tea may increase inorganic phosphate availability leading to elevated mineralization as well as an expedited transition to osteocytes. Whether RR tea modulates mineralization through antioxidant activities or whether other mechanisms are occurring requires future study. Nonetheless, results from this study support the use of supplemental concentrations of RR tea in preclinical in vivo models as the cells produced greater amounts of mineral while displaying no detrimental effects on cell viability and do not appear toxic at the doses studied. Another aspect that should be evaluated further is the safety of higher RR tea concentrations on multiple tissues, as the current study only confirmed safety in an isolated osteoblast cell model and not an entire organism.

A strength of this study is the wide range of concentrations that were encompassed $(0.1-10 \mu \mathrm{g} / \mathrm{mL})$ including RR tea concentrations which could be obtained through diet $(\leq 1 \mu \mathrm{g} / \mathrm{mL}$ of polyphenols) as well as through supplementation ( $\geq 2 \mu \mathrm{g} / \mathrm{mL}$ of polyphenols). Additionally, we investigated physiological concentrations as opposed to supraphysiological studies that have been previously investigated in the literature [60]. However, a limitation is that cells were exposed to RR tea directly rather than the metabolites that may act on bone cells following digestion and absorption. In conclusion, RR tea stimulated osteoblast mineralization in a dose-dependent manner and were accompanied with downregulation of OPN, increased ALP activity, and increased cell activity.

Supplementary Materials: The following are available online at http://www.mdpi.com/2306-5710/5/4/69/s1. Table S1: Forward and reverse primer sequences. Table S2: Immunoblotting protocol for specific proteins.

Author Contributions: M.D.M. and W.E.W conceived and designed the study; M.D.M performed the experiments; M.D.M. analyzed the data; W.E.W. contributed reagents/materials/analysis tools; A.J.M. and W.G. provided technical and experimental support; M.D.M., A.J.M., W.G., and W.E.W. wrote the manuscript.

Funding: This research was supported by a NSERC Discovery Grant (W.E.W.), the Canada Research Chairs program (W.E.W.) and a NSERC Postdoctoral Fellowship (W.G.).

Conflicts of Interest: The authors declare no conflict of interest.

\section{References}

1. Chan, G.K.; Duque, G. Age-related bone loss: Old bone, new facts. Gerontology 2002, 48, 62-71. [CrossRef]

2. Tella, S.H.; Gallagher, J.C. Prevention and treatment of postmenopausal osteoporosis. J. Steroid Biochem. Mol. Biol. 2014, 142, 155-170. [CrossRef] [PubMed]

3. Cauley, J.A. Public health impact of osteoporosis. J. Gerontol. A Biol. Sci. Med. Sci. 2013, 68, $1243-1251$. [CrossRef] [PubMed]

4. Bliuc, D.; Nguyen, N.D.; Nguyen, T.V.; Eisman, J.A.; Center, J.R. Compound risk of high mortality following osteoporotic fracture and refracture in elderly women and men. J. Bone Miner. Res. 2013, 28, 2317-2324. [CrossRef]

5. Magaziner, J.; Fredman, L.; Hawkes, W.; Hebel, J.R.; Zimmerman, S.; Orwig, D.L.; Wehren, L. Changes in functional status attributable to hip fracture: A comparison of hip fracture patients to community-dwelling aged. Am. J. Epidemiol. 2003, 157, 1023-1031. [CrossRef] [PubMed]

6. Cashman, K. Prebiotics and calcium bioavailability. Curr. Issues Intest. Microbiol. 2003, 4, 21-32.

7. Cotter, A.; Cashman, K.D. Genistein appears to prevent early postmenopausal bone loss as effectively as hormone replacement therapy. Nutr. Rev. 2003, 61, 346-351. [CrossRef]

8. Weaver, C.M.; Alekel, D.L.; Ward, W.E.; Ronis, M.J. Flavonoid intake and bone health. J. Nutr. Gerontol. Geriatr. 2012, 31, 239-253. [CrossRef]

9. New, S.A. Intake of fruit and vegetables: Implications for bone health. Proc. Nutr. Soc. 2003, 62, 889-899. [CrossRef]

10. Kruger, M.C.; Tousen, Y.; Katsumata, S.; Tadaishi, M.; Kasonga, A.E.; Deepak, V.; Coetzee, M.; Ishimi, Y. Effects of soy phytoestrogens and New Zealand functional foods on bone health. J. Nutr. Sci. Vitaminol. (Tokyo) 2015, 61, S142-S144. [CrossRef]

11. Nash, L.A.; Ward, W.E. Tea and bone health: Findings from human studies, potential mechanisms, and identification of knowledge gaps. Crit. Rev. Food Sci. Nutr. 2017, 57, 1603-1617. [CrossRef] 
12. Yang, C.S.; Ju, J.; Lu, G.; Xiao, H.; Hao, X.; Sang, S.; Lambert, J.D. Cancer prevention by tea and tea polyphenols. Asia Pac. J. Clin. Nutr. 2008, 17 (Suppl. 1), 245-248.

13. Deka, A.; Vita, J.A. Tea and cardiovascular disease. Pharmacol. Res. 2011, 64, 136-145. [CrossRef] [PubMed]

14. Breiter, T.; Laue, C.; Kressel, G.; Groll, S.; Engelhardt, U.H.; Hahn, A. Bioavailability and antioxidant potential of rooibos flavonoids in humans following the consumption of different rooibos formulations. Food Chem. 2011, 128, 338-347. [CrossRef]

15. McAlpine, M.D.; Ward, W.E. Influence of steep time on polyphenol content and antioxidant capacity of black, green, rooibos, and herbal teas. Beverages 2016, 2, 17. [CrossRef]

16. Hegarty, V.M.; May, H.M.; Khaw, K.T. Tea drinking and bone mineral density in older women. Am. J. Clin. Nutr. 2000, 71, 1003-1007. [CrossRef]

17. Wu, C.H.; Yang, Y.C.; Yao, W.J.; Lu, F.H.; Wu, J.S.; Chang, C.J. Epidemiological evidence of increased bone mineral density in habitual tea drinkers. Arch. Intern. Med. 2002, 162, 1001-1006. [CrossRef]

18. Devine, A.; Hodgson, J.M.; Dick, I.M.; Prince, R.L. Tea drinking is associated with benefits on bone density in older women. Am. J. Clin. Nutr. 2007, 86, 1243-1247. [CrossRef]

19. Zhang, Z.F.; Yang, J.L.; Jiang, H.C.; Lai, Z.; Wu, F.; Liu, Z.X. Updated association of tea consumption and bone mineral density: A meta-analysis. Medicine (Baltim.) 2017, 96, e6437. [CrossRef]

20. Sheng, J.; Qu, X.; Zhang, X.; Zhai, Z.; Li, H.; Liu, X.; Li, H.; Liu, G.; Zhu, Z.; Hao, Y.; et al. Coffee, tea, and the risk of hip fracture: A meta-analysis. Osteoporosis Int. 2014, 25, 141-150. [CrossRef]

21. Chen, B.; Shi, H.F.; Wu, S.C. Tea consumption didn't modify the risk of fracture: A dose-response meta-analysis of observational studies. Diagn. Pathol. 2014, 9, 44. [CrossRef]

22. Das, A.S.; Das, D.; Mukherjee, M.; Mukherjee, S.; Mitra, C. Phytoestrogenic effects of black tea extract (Camellia sinensis) in an oophorectomized rat (Rattus norvegicus) model of osteoporosis. Life Sci. 2005, 77, 3049-3057. [CrossRef]

23. Shen, C.L.; Wang, P.; Guerrieri, J.; Yeh, J.K.; Wang, J.S. Protective effect of green tea polyphenols on bone loss in middle-aged female rats. Osteoporos Int. 2008, 19, 979-990. [CrossRef]

24. Chen, C.H.; Kang, L.; Lin, R.W.; Fu, Y.C.; Lin, Y.S.; Chang, J.K.; Chen, H.T.; Chen, C.H.; Lin, S.Y.; Wang, G.J.; et al. (-)-Epigallocatechin-3-gallate improves bone microarchitecture in ovariectomized rats. Menopause 2013, 20, 687-694. [CrossRef]

25. Shen, C.L.; Yeh, J.K.; Stoecker, B.J.; Chyu, M.C.; Wang, J.S. Green tea polyphenols mitigate deterioration of bone microarchitecture in middle-aged female rats. Bone 2009, 44, 684-690. [CrossRef] [PubMed]

26. Addison, W.N.; Azari, F.; Sorensen, E.S.; Kaartinen, M.T.; McKee, M.D. Pyrophosphate inhibits mineralization of osteoblast cultures by binding to mineral, up-regulating osteopontin, and inhibiting alkaline phosphatase activity. J. Biol. Chem. 2007, 282, 15872-15883. [CrossRef] [PubMed]

27. Sodek, J.; Ganss, B.; McKee, M.D. Osteopontin. Crit. Rev. Oral. Biol. Med. 2000, 11, 279-303. [CrossRef] [PubMed]

28. Bonewald, L.F. The amazing osteocyte. J. Bone Miner. Res. 2011, 26, 229-238. [CrossRef]

29. Bramati, L.; Minoggio, M.; Gardana, C.; Simonetti, P.; Mauri, P.; Pietta, P. Quantitative characterization of flavonoid compounds in Rooibos tea (Aspalathus linearis) by LC-UV/DAD. J. Agric. Food Chem. 2002, 50, 5513-5519. [CrossRef]

30. Chen, C.H.; Ho, M.L.; Chang, J.K.; Hung, S.H.; Wang, G.J. Green tea catechin enhances osteogenesis in a bone marrow mesenchymal stem cell line. Osteoporos Int. 2005, 16, 2039-2045. [CrossRef]

31. Vali, B.; Rao, L.G.; El-Sohemy, A. Epigallocatechin-3-gallate increases the formation of mineralized bone nodules by human osteoblast-like cells. J. Nutr. Biochem. 2007, 18, 341-347. [CrossRef] [PubMed]

32. Nash, L.A.; Ward, W.E. Comparison of black, green and rooibos tea on osteoblast activity. Food Funct. 2016, 7, 1166-1175. [CrossRef]

33. Liang, Q.; Lv, M.; Zhang, X.; Hu, J.; Wu, Y.; Huang, Y.; Wang, X.; Sheng, J. Effect of black tea extract and thearubigins on osteoporosis in rats and osteoclast formation in vitro. Front. Physiol. 2018, 9, 1225. [CrossRef]

34. Oka, Y.; Iwai, S.; Amano, H.; Irie, Y.; Yatomi, K.; Ryu, K.; Yamada, S.; Inagaki, K.; Oguchi, K. Tea polyphenols inhibit rat osteoclast formation and differentiation. J. Pharmacol. Sci. 2012, 118, 55-64. [CrossRef]

35. Nash, L.A.; Sullivan, P.J.; Peters, S.J.; Ward, W.E. Rooibos flavonoids, orientin and luteolin, stimulate mineralization in human osteoblasts through the Wnt pathway. Mol. Nutr. Food Res. 2015, 59, 443-453. [CrossRef] 
36. Moosa, S.; Kasonga, A.E.; Deepak, V.; Marais, S.; Magoshi, I.B.; Bester, M.J.; Kruger, M.C.; Coetzee, M. Rooibos tea extracts inhibit osteoclast formation and activity through the attenuation of NF-kappaB activity in RAW264.7 murine macrophages. Food Funct. 2018, 9, 3301-3312. [CrossRef]

37. Kurahashi, N.; Sasazuki, S.; Iwasaki, M.; Inoue, M.; Tsugane, S.; Group, J.S. Green tea consumption and prostate cancer risk in Japanese men: A prospective study. Am. J. Epidemiol. 2008, 167, 71-77. [CrossRef]

38. Neyestani, T.R.; Shariatzade, N.; Kalayi, A.; Gharavi, A.; Khalaji, N.; Dadkhah, M.; Zowghi, T.; Haidari, H.; Shab-bidar, S. Regular daily intake of black tea improves oxidative stress biomarkers and decreases serum C-reactive protein levels in type 2 diabetic patients. Ann. Nutr. Metab. 2010, 57, 40-49. [CrossRef]

39. Tan, E.K.; Tan, C.; Fook-Chong, S.M.; Lum, S.Y.; Chai, A.; Chung, H.; Shen, H.; Zhao, Y.; Teoh, M.L.; Yih, Y.; et al. Dose-dependent protective effect of coffee, tea, and smoking in Parkinson's disease: A study in ethnic Chinese. J. Neurol. Sci. 2003, 216, 163-167. [CrossRef]

40. Fogh, J.; Fogh, J.M.; Orfeo, T. One hundred and twenty-seven cultured human tumor cell lines producing tumors in nude mice. J. Natl. Cancer Inst. 1977, 59, 221-226. [CrossRef]

41. Kedare, S.B.; Singh, R.P. Genesis and development of DPPH method of antioxidant assay. J. Food Sci. Technol. 2011, 48, 412-422. [CrossRef]

42. Lazcano, O.; Li, C.Y.; Pierre, R.V.; O’Duffy, J.D.; Beissner, R.S.; Abell-Aleff, P.C. Clinical utility of the alizarin red S stain on permanent preparations to detect calcium-containing compounds in synovial fluid. Am. J. Clin. Pathol. 1993, 99, 90-96. [CrossRef]

43. Tada, H.; Shiho, O.; Kuroshima, K.; Koyama, M.; Tsukamoto, K. An improved colorimetric assay for interleukin 2. J. Immunol. Methods 1986, 93, 157-165. [CrossRef]

44. MacNeil, A.J.; Jiao, S.C.; McEachern, L.A.; Yang, Y.J.; Dennis, A.; Yu, H.; Xu, Z.; Marshall, J.S.; Lin, T.J. MAPK kinase 3 is a tumor suppressor with reduced copy number in breast cancer. Cancer Res. 2014, 74, 162-172. [CrossRef]

45. Sabokbar, A.; Millett, P.J.; Myer, B.; Rushton, N. A rapid, quantitative assay for measuring alkaline phosphatase activity in osteoblastic cells in vitro. Bone Miner. 1994, 27, 57-67. [CrossRef]

46. Pochmann, D.; Innocente, A.M.; Buffon, A.; Freitas Sarkis, J.J.; Porciuncula, L.O. Biochemical characterization of an ectonucleotide pyrophosphatase/phosphodiesterase (E-NPP, E.C. 3.1.4.1) from rat cardiac soluble and microsomal fractions. J. Enzyme Inhib. Med. Chem. 2012, 27, 29-36. [CrossRef]

47. Romagnoli, C.; Marcucci, G.; Favilli, F.; Zonefrati, R.; Mavilia, C.; Galli, G.; Tanini, A.; Iantomasi, T.; Brandi, M.L.; Vincenzini, M.T. Role of GSH/GSSG redox couple in osteogenic activity and osteoclastogenic markers of human osteoblast-like SaOS-2 cells. FEBS J. 2013, 280, 867-879. [CrossRef]

48. Arai, M.; Shibata, Y.; Pugdee, K.; Abiko, Y.; Ogata, Y. Effects of reactive oxygen species (ROS) on antioxidant system and osteoblastic differentiation in MC3T3-E1 cells. IUBMB Life 2007, 59, 27-33. [CrossRef]

49. Ueno, T.; Yamada, M.; Igarashi, Y.; Ogawa, T. N-acetyl cysteine protects osteoblastic function from oxidative stress. J. Biomed. Mater. Res. A 2011, 99, 523-531. [CrossRef]

50. Almeida, M.; Han, L.; Martin-Millan, M.; Plotkin, L.I.; Stewart, S.A.; Roberson, P.K.; Kousteni, S.; O’Brien, C.A.; Bellido, T.; Parfitt, A.M.; et al. Skeletal involution by age-associated oxidative stress and its acceleration by loss of sex steroids. J. Biol. Chem. 2007, 282, 27285-27297. [CrossRef]

51. Bai, X.C.; Lu, D.; Bai, J.; Zheng, H.; Ke, Z.Y.; Li, X.M.; Luo, S.Q. Oxidative stress inhibits osteoblastic differentiation of bone cells by ERK and NF-kappaB. Biochem. Biophys. Res. Commun. 2004, 314, 197-207. [CrossRef]

52. Yamada, M.; Ueno, T.; Minamikawa, H.; Sato, N.; Iwasa, F.; Hori, N.; Ogawa, T. N-acetyl cysteine alleviates cytotoxicity of bone substitute. J. Dent. Res. 2010, 89, 411-416. [CrossRef]

53. Jun, J.H.; Lee, S.H.; Kwak, H.B.; Lee, Z.H.; Seo, S.B.; Woo, K.M.; Ryoo, H.M.; Kim, G.S.; Baek, J.H. $\mathrm{N}$-acetylcysteine stimulates osteoblastic differentiation of mouse calvarial cells. J. Cell. Biochem. 2008, 103, 1246-1255. [CrossRef]

54. Huh, Y.J.; Kim, J.M.; Kim, H.; Song, H.; So, H.; Lee, S.Y.; Kwon, S.B.; Kim, H.J.; Kim, H.H.; Lee, S.H.; et al. Regulation of osteoclast differentiation by the redox-dependent modulation of nuclear import of transcription factors. Cell Death Differ. 2006, 13, 1138-1146. [CrossRef]

55. Jilka, R.L.; Noble, B.; Weinstein, R.S. Osteocyte apoptosis. Bone 2013, 54, 264-271. [CrossRef]

56. Shen, C.L.; Chyu, M.C.; Yeh, J.K.; Zhang, Y.; Pence, B.C.; Felton, C.K.; Brismee, J.M.; Arjmandi, B.H.; Doctolero, S.; Wang, J.S. Effect of green tea and Tai Chi on bone health in postmenopausal osteopenic women: A 6-month randomized placebo-controlled trial. Osteoporos Int. 2012, 23, 1541-1552. [CrossRef] 
57. Lyle, A.N.; Joseph, G.; Fan, A.E.; Weiss, D.; Landazuri, N.; Taylor, W.R. Reactive oxygen species regulate osteopontin expression in a murine model of postischemic neovascularization. Arterioscler. Thromb. Vasc. Biol. 2012, 32, 1383-1391. [CrossRef]

58. Prideaux, M.; Wijenayaka, A.R.; Kumarasinghe, D.D.; Ormsby, R.T.; Evdokiou, A.; Findlay, D.M.; Atkins, G.J. SaOS2 Osteosarcoma cells as an in vitro model for studying the transition of human osteoblasts to osteocytes. Calcif. Tissue Int. 2014, 95, 183-193. [CrossRef]

59. Burgers, T.A.; Williams, B.O. Regulation of Wnt/beta-catenin signaling within and from osteocytes. Bone 2013, 54, 244-249. [CrossRef]

60. Nash, L.A.; Peters, S.J.; Sullivan, P.J.; Ward, W.E. Supraphysiological levels of quercetin glycosides are required to alter mineralization in Saos2 cells. Int. J. Environ. Res. Public Health 2016, 13, 460. [CrossRef]

(C) 2019 by the authors. Licensee MDPI, Basel, Switzerland. This article is an open access article distributed under the terms and conditions of the Creative Commons Attribution (CC BY) license (http://creativecommons.org/licenses/by/4.0/). 